\title{
Experimental Study on Waste Engine Oil Processing by Means of Flocculation-absorption
}

\author{
Ming-yuan LIU ${ }^{1,}$, , Lin ZHOU ${ }^{1}$, Yun-ying SHA ${ }^{1}$ and Zhong-hua \\ WANG $^{1}$ \\ ${ }^{1}$ School of Pharmacy, Taizhou Polytechnic College, Taizhou, Jiangsu, China \\ *Corresponding author: Imyliu_128@163.com
}

Keywords: Waste Engine oil, Flocculation, Absorption, Active White Clay, Re-purging.

\begin{abstract}
Re-cleansing and purification of waste engine oil by flocculation-absorption can be used as a pretreatment for further refined processing due to its features of low pollution, low cost and easy operability. This paper has sifted through various absorbents to locate the most appropriate one based on previous flocculation experiments, then to obtain optimal operational parameters. Experiments have demonstrated that best purification effect could be achieved under the following conditions: $12 \% \sim 14 \%(\mathrm{~W} / \mathrm{V})$ active white clay at the reaction temperature of $120^{\circ} \mathrm{C} \sim 130^{\circ} \mathrm{C}$ for about $30 \mathrm{~min}$. Chrominance and quality of waste engine oil could be markedly enhanced after flocculation-absorption method.
\end{abstract}

\section{Foreword}

Impurities like carbon deposits, colloid, and acid materials occur during the process of engine oil as a consequence of long-time contact with high-temperature generator triggering pyrolization and polymerization. [1] Meanwhile, other factors can cause quality deterioration of engine oil owing to friction-generating metal particles and moisture caused by combustion as well as the above-mentioned impurities. Degraded engine oil is characterized by color darkening, viscosity rising, acid value increasing and suspension appearing. However, lubricants can achieve70\% 75\% (W)basic oil recycling rate after removal of impurities and metamorphous materials [2].

Up to now, regeneration methods of waste engine oil worldwide are mainly as follows: re-purging, re-purification, refinement, among which the former is the prerequisite and basis of the latter, that is, further refinement after re-purification. Re-purging procedure aims to remove moisture, sludge and impurities existing stably in the form of colloid[3] with major processing techniques as precipitation, centrifuge, filtration, flocculation, absorption and so on [4]. This paper used waste engine oil recycled from certain $4 \mathrm{~s}$ automobile store to be our research subject to be re-purified by flocculation-absorption. After selecting proper coagulant and absorbent, this paper also figures out the most influential factors and optimal parameters amid flocculation-absorption, and in the meantime, we can witness oil quality levelling up after treatment.

\section{Experiments}

\section{Materials in Experiments}

Flocculent: N-(2-Hydroxyethyl) ethylenediamine.

Absorbent: active white clay; macroporous resin; activated carbon powder; activated carbon particles 


\section{Procedures}

Dilute waste engine oil sample with mineral ether and put the solution to test in TU-18010 UV-spectrophotometer to obtain its maximum absorption wave length as $475 \mathrm{~nm}$, and light transmittance rate as $1.68 \%$.

Prepare $100 \mathrm{ml}$ waste engine oil; then add certain amount of $\mathrm{N}-(2-\mathrm{Hydroxyethyl})$ ethylenediamine at preset temperature; stir for some time and keep it at constant $80^{\circ} \mathrm{C}$ for 2 hours' precipitation. Put the absorbent into filtered oil sample, then stirring for some time and keeping it at $80^{\circ} \mathrm{C}$ for 3 hours' depositing so as to harvest re-purging oil. Dilute re-purging oil with mineral ether [5-6], then put this under UV-spectrophotometer against the parameter of mineral ether at $475 \mathrm{~nm}$ wave length to gain its light transmittance rate. The final step is to observe transmittance light variables to get tentative absorption effects after rough reaction in order to figure out the ideal absorption parameters.

\section{Experiment Results of Flocculation Treatment}

Coupled with flocculation selective trials and single factor \& orthogonal experiments, the optimal flocculation parameters of waste engine oil by means of $20 \% \mathrm{~V} / \mathrm{V}$ $\mathrm{N}-(2-H y d r o x y e t h y l)$ ethylenediamine solution are listed below:

Table 1. Optimal parameters of re-purification of waste engine oil by flocculants

\begin{tabular}{|l|l|l|l|}
\hline Flocculent & $\begin{array}{l}\text { Optimal } \\
\text { dosage } \\
(\%)\end{array}$ & $\begin{array}{l}\text { Optimal } \\
\text { reactions } \\
\text { temperature }\left({ }^{\circ} \mathrm{C}\right)\end{array}$ & $\begin{array}{l}\text { Optimal } \\
\text { stirring } \\
\text { time }(\mathrm{min})\end{array}$ \\
\hline N-(2-Hydroxyethyl)ethylenediamine & $10(\mathrm{~V} / \mathrm{V})$ & 80 & 8 \\
$10(\mathrm{~V} / \mathrm{V})$ & 80 & 8 \\
\hline
\end{tabular}

\section{Selection of Absorbents}

After the flocculation of sample oil, we can conduct respective absorption treatment at certain temperature employing absorbents like active white clay, macroporous resin, activated carbon powder, activated carbon particles, as previously depicted in chapter 2.2. After absorption treatment, we can put the oil sample to filtration and to testing its light transmittance rate in order to fathom out best dosage as listed in fig. 2: best absorption result was found with use of active white clay.

Table 2. Transmittance variables by use of different absorbents

\begin{tabular}{|l|l|l|l|l|}
\hline Absorbent & $\begin{array}{l}\text { Macroporous } \\
\text { resin }\end{array}$ & $\begin{array}{l}\text { Active white } \\
\text { clay }\end{array}$ & $\begin{array}{l}\text { Activated carbon } \\
\text { powder }\end{array}$ & $\begin{array}{l}\text { Activated } \\
\text { carbon } \\
\text { particles }\end{array}$ \\
\hline $\mathrm{T}(\%)$ & 40.08 & 60.12 & 56.77 & 42.34 \\
\hline
\end{tabular}

\section{Optimal Absorbent Parameters}

Optimal Dosage of Active White Clay. Insufficient dose of active white clay cannot fully absorb impurities in waste engine oil whereas excessive amount results in difficult filtering, increased duration, bigger waste deposits and decreased de-colorization. As seen in fig.1, light transmittance rate achieves top level with optimal absorption de-coloring effect when the ratio of active white clay in use ranges between $12 \% \sim 14 \%(\mathrm{~W} / \mathrm{V})$.

Optimal Reaction Temperature of Active White Clay. Absorption effect is not good at excessive low temperature as a result of high viscosity rate in oil sample while light transmittance is not obvious at excessive high reaction temperature because oil 
sample is oxidized causing decreased decoloring effect. As shown in fig.2, when reaction temperature of absorption reaches around $120^{\circ} \mathrm{C} \sim 130^{\circ} \mathrm{C}$, light transmittance rate gets to the highest point along with best absorption decoloring effect.

Optimal Absorption Time of Active White Clay. Insufficient absorption reaction can happen when absorption time is too short in that balanced absorption fails to achieve. In contrast, long-time absorption leads to high reaction costs along with mundane de-coloring effect. As illustrated in fig.3, light transmittance rate reaches the highest with best de-coloring effect when the reaction time approximates $30 \mathrm{~min}$.

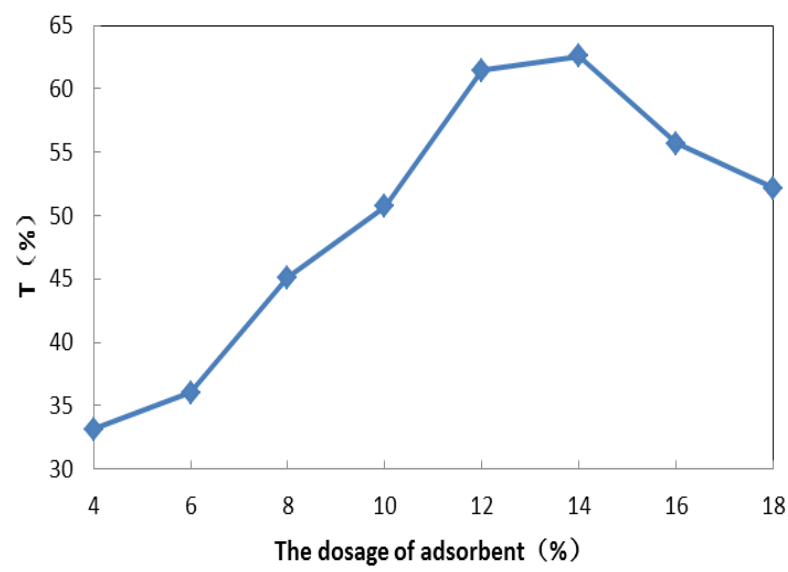

Figure 1. Optimal dosage of absorbent

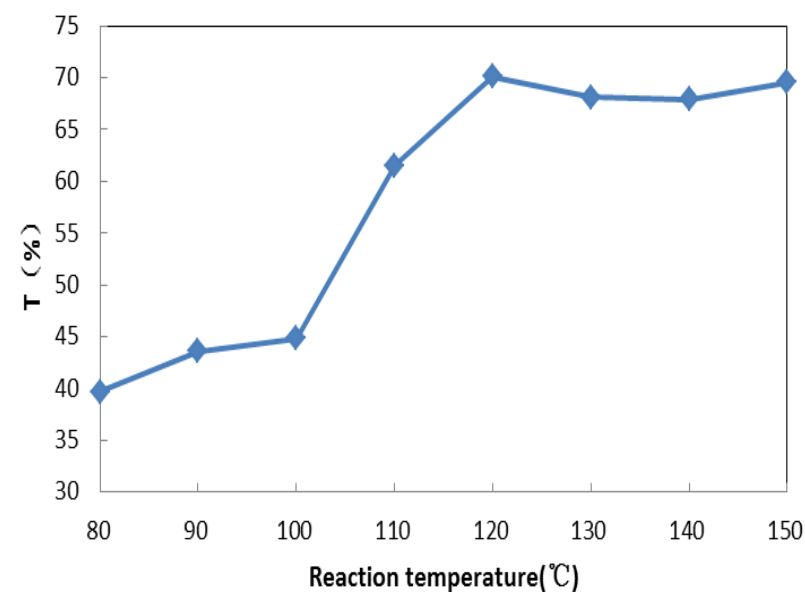

Figure 2. Optimal reaction temperature of absorbent

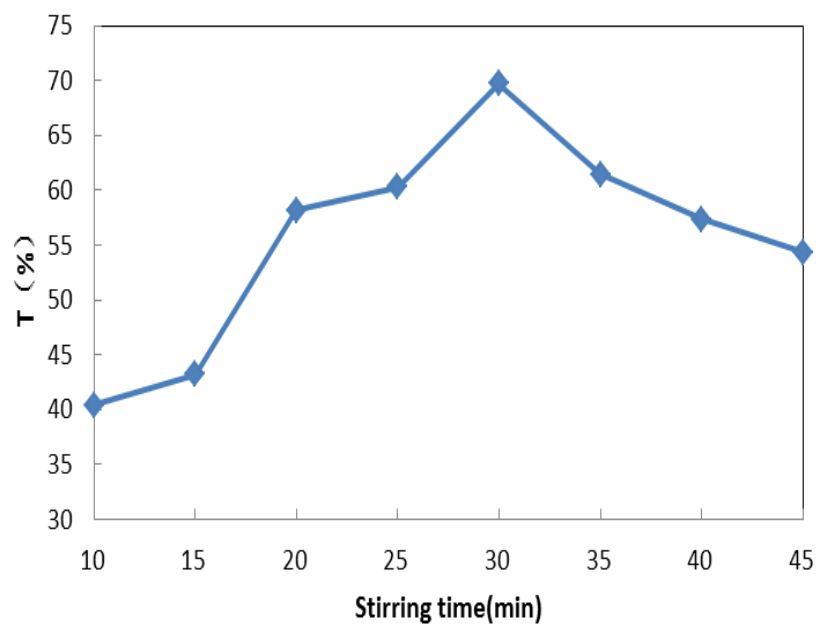

Figure 3. Optimal stirring time of absorbent 


\section{Effect of Flocculation-absorption Treatment}

After being treated by the method of flocculation-absorption, waste oil engine has improved on its chrominance and quality. Depicted in fig.3, this kind of operation technique is easy and cost-friendly, which reduces treatment difficulties of the subsequent refining stage.

Table 3. Quality contrast of re-purging oil sample by flocculation-absorpion

\begin{tabular}{|l|l|l|}
\hline Task & $\begin{array}{l}\text { Re-purging } \\
\text { oil }\end{array}$ & $\begin{array}{l}\text { Waste engine } \\
\text { oil }\end{array}$ \\
\hline Acid value $/ \mathrm{mgKOH} \cdot \mathrm{g}^{-1}$ & 0.44 & 1.83 \\
\hline $\begin{array}{l}\text { Dynamic viscosity } / \mathrm{mm}^{2} \cdot \mathrm{s}^{-1}, \\
40^{\circ} \mathrm{C}\end{array}$ & 73.31 & 81.74 \\
\hline Mechanical impurities $/ \%$ & 0.135 & 3.17 \\
\hline Chroma /number & 4 & $>8$ \\
\hline
\end{tabular}

\section{Reference}

[1] Zhang Xianming, Cao Hualing, Li Chuan. Study on the Contamination and Purification System of Running-in Engine Oil [J]. Lubrication Engineering, (2007) 32(1):167-169.

[2] Li Yanhong, Wu Jiejiao, Jiang Guoquan, etc. Progresses in Regeneration Technologies for Used Lube Oils [J]. Petrochemical Technology, (2016)45(2):244-250.

[3] Zheng Fazheng, Xie Feng. Properties and Applications of Lubricants [M].Bei Jing: Sinopec Press (2006).

[4] Xiong Daoling, Yang Jinxin, Zhang Tuanjie, etc. Research Progresses in Waste Oil Regeneration $[\mathrm{J}]$. Chemical Industry and Engineering Progress, (2014)33(10):2778-2784 .

[5] Xi Danli, Sun Yusheng, Liu Xiuying. Environmental Monitoring. Bei Jing: Higher Education Press (2003).

[6] Chen Shijiang. Study on Regeneration Technology for Waste Lubricating Oil Flocculation Absorption [D].Xi An: Chang'an University, (2010) 35-39. 